\title{
Prática de discussão coletiva de uma professora em Álgebra
}

\author{
Discussion practice of a teacher in Algebra
}

\author{
Cátia Rodrigues ${ }^{1}$ \\ João Pedro da Ponte ${ }^{2}$ \\ Luís Menezes ${ }^{3}$
}

\begin{abstract}
Resumo
Este artigo apresenta um estudo que tem como objetivo descrever e compreender a prática de discussão matemática de uma professora durante a preparação e dinamização da discussão coletiva em Álgebra com alunos do $7 .^{\circ}$ ano. $\mathrm{O}$ estudo segue uma abordagem qualitativa e interpretativa com um design de estudo de caso de uma professora de Matemática. Os resultados revelam que a professora seleciona criteriosamente as tarefas que pretende apresentar aos alunos, antecipando possíveis estratégias de resolução que recorrem à tentativa e erro e ao uso de linguagem algébrica. Em aula, na dinamização da discussão, concretiza a preparação feita, levando os alunos a apresentar as suas estratégias de resolução, a comparar e avaliar as dos colegas, filtrando os diversos contributos, de modo a que sejam sintetizados os aspetos mais relevantes do seu trabalho. A professora leva os alunos a generalizar e justificar ideias algébricas, através de uma combinação intencional de ações de elicitar, apoiar, informar e desafiar.
\end{abstract}

Palavras-chave: Discussões coletivas; Prática letiva; Conhecimento didático; Álgebra.

\begin{abstract}
This article presents a study that aims to describe and to understand the mathematical discussion practice of a teacher during the preparation and promotion of a collective discussion in Algebra with 7th grade students. The study follows a qualitative and interpretative approach and follows a case study design of a mathematics teacher. The results show that the teacher begins by carefully selects the task she intends to present to the students, anticipating possible strategies for resolving the problem, using algebraic language. In class, in the promotion of the discussion, he/she concretizes the preparation made leading the students to present their strategies of resolution, to compare and evaluate the colleagues, filtering the various contributions, so that the most relevant aspects of their work are synthesized. The teacher leads students to generalize and justify algebraic ideas, by combining intentional actions of eliciting, supporting, informing and challenging.
\end{abstract}

Keywords: Collective discussions; Learner practice; Didactic knowledge; Algebra.

\section{Submetido em: 08/02/2018 - Aceito em: 30/07/2018 - Publicado em: 06/08/2018}

1 Doutoranda em Educação, especialidade em Didática da Matemática, no Instituto de Educação da Universidade de Lisboa. Professora na Escola Básica e Secundária de Sever do Vouga, Portugal. Email: catiamat@gmail.com.

${ }^{2}$ Doutor em Mathematics Education pela University of Georgia, EUA. Professor catedrático do Instituto de Educação da Universidade de Lisboa, Portugal. Email: jpponte@ie.ulisboa.pt.

${ }^{3}$ Doutor em Didática da Matemática pela Universidade de Lisboa. Professor do Instituto Politécnico de Viseu, Portugal. Email: menezes@esev.ipv.pt. 


\section{Introdução}

DOI: https://doi.org/10.20396/zet.v26i3.8651653

A criação de um ambiente de aprendizagem onde os alunos sejam desafiados a trabalhar com tarefas matematicamente significativas e a apresentar e justificar as suas estratégias de resolução, argumentando e negociando significados para os raciocínios emergentes, tem forte impacto na sua aprendizagem (Cengiz, Kline \& Grant, 2011; Ponte \& Quaresma, 2016; Guerreiro, Ferreira, Menezes \& Martinho, 2015; Stein, Engle, Smith \& Hughes, 2008). Quando estas tarefas incidem nos temas da Álgebra, as discussões coletivas podem contribuir para o desenvolvimento das capacidades de generalização e de simbolização dos alunos. Com vista a envolver os alunos em discussões coletivas, o professor precisa de desempenhar um conjunto de ações instrucionais (Cengiz et al., 2011; Ponte, Mata-Pereira \& Quaresma, 2013) que se apoiam no seu conhecimento didático (Ponte, 2012).

Neste artigo, analisamos a prática de discussão de uma professora de Matemática, que ensina ao $7 .^{\circ}$ ano, procurando descrever e compreender como prepara e dinamiza a discussão coletiva em sala de aula, a partir do trabalho dos alunos com tarefas algébricas, em articulação com o seu conhecimento didático da Matemática. Na fase de preparação, focamos as tarefas que seleciona, as estratégias de resolução que antecipa e como pensa promover a discussão. Na fase de dinamização da discussão, analisamos como usa a preparação para orquestrar a discussão, identificando as ações que executa para levar os alunos a apresentar, justificar e argumentar sobre ideias algébricas.

\section{Prática de discussão matemática e conhecimento didático}

A promoção de discussões matemáticas coletivas em sala de aula é uma abordagem pedagógica com fortes potencialidades para a aprendizagem dos alunos, na medida em que estes são chamados a apresentar diversas estratégias de resolução de tarefas matemáticas ricas, a justificar os raciocínios usados, a argumentar sobre os raciocínios dos colegas e a sistematizar os principais conceitos resultantes dessa discussão. A dinamização deste tipo de aulas é particularmente desafiante para o professor. Stein et al. (2008) propõem um modelo de cinco práticas para organizar e orquestrar uma discussão coletiva produtiva. Através da prática de antecipar, o professor inicia a preparação da discussão coletiva com a antecipação de possíveis estratégias de resolução a apresentar pelos alunos, de prováveis dificuldades que podem enfrentar e formas de as ultrapassar. De seguida, em sala de aula, acompanha o trabalho dos alunos e identifica os conceitos, as representações e as dificuldades que estes enfrentam - monitorizar. Esta prática não envolve apenas ouvir ou observar o que os alunos fazem, mas também ajudá-los a progredir no seu trabalho, colocando boas questões (Smith \& Stein, 2011). Em simultâneo com essa prática, o professor pensa em estratégias de resolução que têm potencial para serem apresentadas em coletivo - selecionar - e como vai organizar essas apresentações, com vista a envolver os alunos nas ideias que pretende analisar sequenciar. A tomada de decisão sobre as estratégias a selecionar e como as sequenciar é suportada pela antecipação feita aquando da planificação. Por fỉm, dá início à discussão, apoiando-se nas práticas anteriores, levando os alunos a comparar as diversas estratégias apresentadas, a relacionar representações, a justificar raciocínios e a argumentar sobre os Zetetiké, Campinas, SP, v.26, n.3, set./dez.2018, p.486-505 
DOI: https://doi.org/10.20396/zet.v26i3.8651653

raciocínios dos colegas - estabelecer conexões entre as respostas dos alunos. Nesta prática, o professor pode introduzir ideias novas na discussão, como estratégias de resolução ou representações diferentes das apresentadas. Esta prática é particularmente exigente, por ter em vista tornar os conceitos matemáticos compreensíveis aos alunos. Para tal, o questionamento do professor é fundamental, ao contribuir para que os alunos clarifiquem e aprofundem os seus raciocínios (Guerreiro et al., 2015; Smith et al., 2011; Menezes, Guerreiro, Martinho \& Tomás Ferreira, 2013). O professor deve ter consciência de que na dinamização da discussão em sala de aula pode ser surpreendido com ideias diferentes das antecipadas, tendo de ser capaz de decidir se são importantes para seguir ou devem ser abandonadas. Smith et al. (2011) referem, ainda, que o modelo anterior é precedido da prática zero referente à definição do objetivo que se pretende atingir (propósito da discussão).

Após o trabalho autónomo dos alunos, o professor pode organizar a discussão coletiva em três momentos: $i$ ) apresentação de ideias; ii) comparação e avaliação; e iii) filtragem (Sherin, 2002). No primeiro, os alunos são convidados a apresentar as suas estratégias de resolução e a explicar o raciocínio seguido, podendo o professor assumir diferentes atuações para promover essa apresentação: iniciar pelas mais frequentes ou pelas que mobilizam linguagem matemática informal, dependendo do seu objetivo. No segundo momento, os alunos são convidados a relacionar as estratégias apresentadas pelos colegas, procurando pontos convergentes ou divergentes entre elas, avaliando os raciocínios apresentados e as justificações oferecidas. No terceiro, o professor foca a atenção dos alunos em aspetos particulares das estratégias ou das justificações, com vista a analisar raciocínios que são importantes para atingir o propósito da discussão.

Durante a discussão, o professor tem objetivos distintos para o discurso dos alunos que está a promover (Sherin, 2002), já que numa primeira fase tem interesse em ter diversas estratégias de resolução para análise, não se preocupando tanto com o seu conteúdo conteúdo matemático não filtrado - incidindo a sua ação na solicitação e discussão de muitas ideias. Perante o que é partilhado, começa a interessar-se por analisar raciocínios particulares - conteúdo matemático filtrado - focando a atenção dos alunos nesses raciocínios filtragem. A análise desses raciocínios leva o professor a voltar à primeira ação - solicitação e discussão de muitas ideias - com a finalidade de aprofundar ou clarificar esses raciocínios que estão nesse momento em análise.

O envolvimento dos alunos numa discussão coletiva é uma atividade intensa para o professor, que é chamado a desempenhar diversas ações de ensino, de acordo com o momento da discussão em que os alunos se encontram e com o discurso que pretende promover. Assim, Cengiz et al. (2011) propõem as seguintes ações de ensino: ações de elicitar, que têm como objetivo levar os alunos a apresentar as suas estratégias de resolução; ações de apoiar, que visam envolver o aluno na discussão através do recordar o objetivo da tarefa ou da discussão, sugerir raciocínios ou representações para interpretação, repetir argumentos e reforçar intervenções do aluno; ações de ampliar, que pretendem levar os alunos a avaliar argumentos, comparar e relacionar estratégias, justificar raciocínios e usar a mesma estratégia em novas situações. Pelo seu lado, Ponte et al. (2013) sugerem que o 
DOI: https://doi.org/10.20396/zet.v26i3.8651653

professor se apoia em quatro tipos de ações para promover a discussão: convidar; apoiar/guiar; informar/sugerir e desafiar. Com as ações de convidar, o professor visa levar os alunos a apresentar as suas estratégias de resolução. Com as outras ações, o professor pretende dinamizar a discussão, em particular, com as de apoiar/guiar, ajuda o aluno a progredir com as suas explicações, justificações e a relacionar ideias; com as de informar/sugerir, introduz ideias na discussão ou valida respostas dos alunos; e com as de desafiar, incentiva o aluno a justificar e relacionar raciocínios, a argumentar sobre os dos colegas e a introduzir e negociar representações. Este modelo tem aspetos em comum com o de Cengiz et al. (2011), principalmente nos propósitos globais das ações do professor, na medida em que as primeiras pretendem introduzir o aluno na discussão, sendo as restantes realizadas para promover a sua continuidade na discussão.

A realização dessas ações na dinamização de uma discussão é apoiada no conhecimento do professor, que se carateriza por ser multifacetado. Ponte (2012) refere-se a este conhecimento do professor como conhecimento didático, encarando-o numa perspetiva integradora, onde estão implicados quatro domínios fundamentais (Figura 1).

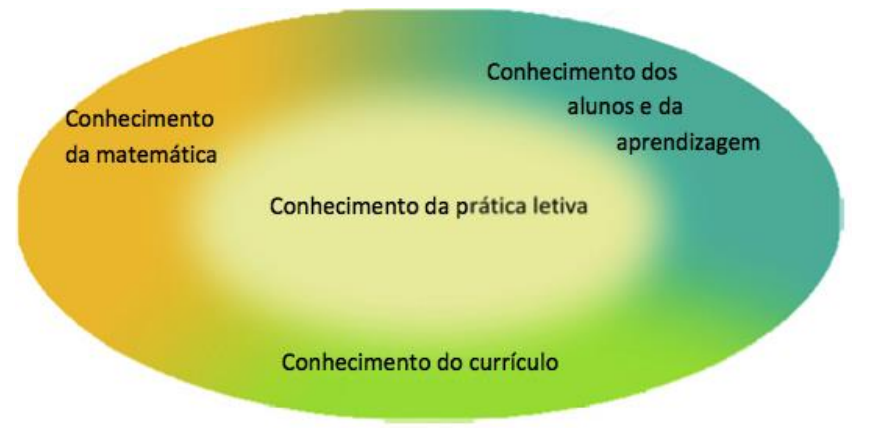

Figura 1 - Domínios do conhecimento didático

Fonte: Adaptado de Ponte, (2012, p. 87).

O conhecimento da Matemática envolve o conhecimento de conceitos, definições, exemplos, representações e conexões, neste caso, os que respeitam à Álgebra. $\mathrm{O}$ conhecimento da prática letiva pressupõe o conhecimento sobre as tarefas a apresentar aos alunos e modo de trabalho mais adequado na sua resolução e como promover a comunicação em sala de aula. O conhecimento do currículo está relacionado com o conhecimento do programa de matemática e de materiais curriculares que podem apoiar o ensino. $\mathrm{O}$ conhecimento dos alunos e da aprendizagem supõe que o professor conheça bem os seus alunos e como estes aprendem.

\section{Metodologia}

$\mathrm{Na}$ medida em que se procura descrever e compreender a prática de discussão matemática de uma professora optou-se por uma abordagem interpretativa e qualitativa. $\mathrm{O}$ design é de estudo de caso de uma professora de Matemática (Ana) a lecionar ao 7. ${ }^{\circ}$ ano, com 
DOI: https://doi.org/10.20396/zet.v26i3.8651653

vista a compreender detalhadamente a sua prática na preparação e dinamização da discussão (Ponte, 2006).

A recolha de dados assenta em três instrumentos principais: a observação participante (OP) (de aulas e das sessões do grupo colaborativo (GC) no âmbito do Projeto Práticas de discussão matemática no ensino da Álgebra (PPDMEA), descritas mais à frente, a entrevista semiestruturada (E) (uma no início e outra no fim do estudo) e análise documental (dos trabalhos dos alunos e do relatório individual da professora), apoiados na elaboração de notas de campo (NC). A opção pela OP tem em vista observar a professora em sala de aula e na sua participação nas sessões de trabalho no GC. Com a entrevista procuramos recolher dados captando a voz da participante, em duas fases do estudo: a entrevista inicial (EI) visa dar a conhecer aspetos profissionais e a entrevista final (EF) objetiva apreciar a sua visão face ao trabalho desenvolvido no GC. As entrevistas e as sessões do GC foram gravadas em áudio e as aulas em vídeo. A investigadora (primeira autora) assume o papel de observadora participante enquanto elemento ativo do GC e apoiando pontualmente, na aula da professora, os alunos no seu trabalho individual. Os trabalhos dos alunos e o relatório individual (RI) elaborado pela professora no âmbito do Projeto PPDMEA complementam os dados fornecidos pelos outros instrumentos de recolha.

A análise de dados baseia-se na análise de conteúdo e definição de categorias de codificação, tendo início com a recolha de dados. Os dados foram analisados, à luz dos modelos teóricos revistos, com vista à identificação de regularidades que originaram a formulação de diversas categorias (Bardin, 1994). Seguidamente, foi feita uma primeira tentativa de organizar os dados recolhidos nessas categorias, de modo a verificar a sua viabilidade e a proceder a ajustamentos, que culminaram no abandono de algumas categorias e na definição de outras, até se alcançar as fixadas no Tabela 1, resultantes de um processo de articulação recursivo de categorias a priori e a posteriori como concretizações de temas estabelecidos para as dimensões: Preparação e Dinamização da discussão coletiva e conhecimento didático.

Tabela 1 - Dimensões, Temas e Categorias de análise de dados 
DOI: https://doi.org/10.20396/zet.v26i3.8651653

\begin{tabular}{|c|c|c|}
\hline Dimensão & Temas & Categorias definidas \\
\hline \multirow{5}{*}{$\begin{array}{c}\text { Preparação da discussão } \\
\text { coletiva }\end{array}$} & $\begin{array}{l}\text { Tarefas e Propósito da } \\
\text { discussão }\end{array}$ & $\begin{array}{l}\text { Natureza; desafio; contexto; } \\
\text { representações }\end{array}$ \\
\hline & & $\begin{array}{l}\text { Conceitos matemáticos e } \\
\text { objetivos específicos; } \\
\text { generalização }\end{array}$ \\
\hline & Estratégias de resolução & $\begin{array}{l}\text { Tentativa e erro; tabela; } \\
\text { algébrica }\end{array}$ \\
\hline & $\begin{array}{l}\text { Seleção de estratégias e } \\
\text { Trajetórias de sequenciação }\end{array}$ & Representações \\
\hline & & $\begin{array}{l}\text { Linguagem matemática } \\
\text { informal; linguagem } \\
\text { matemática formal }\end{array}$ \\
\hline \multirow[t]{3}{*}{$\begin{array}{c}\text { Dinamização da discussão } \\
\text { coletiva }\end{array}$} & $\begin{array}{l}\text { Componentes da discussão, } \\
\text { discurso }\end{array}$ & $\begin{array}{l}\text { Apresentação; comparação, } \\
\text { avaliação e filtragem; } \\
\text { conclusão }\end{array}$ \\
\hline & & $\begin{array}{l}\text { Solicitação e discussão de } \\
\text { muitas ideias; filtragem; } \\
\text { solicitação e discussão de } \\
\text { muitas ideias; conteúdo } \\
\text { matemático filtrado; } \\
\text { conteúdo matemático não } \\
\text { filtrado }\end{array}$ \\
\hline & Ações de ensino & $\begin{array}{l}\text { Elicitar; Apoiar; Informar; } \\
\text { Desafiar }\end{array}$ \\
\hline Conhecimento didático & $\begin{array}{l}\text { Conhecimento didático } \\
\text { sobre a promoção da } \\
\text { discussão }\end{array}$ & $\begin{array}{l}\text { Currículo; alunos e } \\
\text { aprendizagem; prática letiva; } \\
\text { Matemática }\end{array}$ \\
\hline
\end{tabular}

Fonte: Autores do estudo

No tema componentes da discussão, nas ações de ensino, usamos as categorias ações de elicitar (cujo objetivo é levar os alunos a apresentar as suas estratégias de resolução), apoiar (visando ajudar o aluno a progredir na sua apresentação, explicação e justificação), informar (com o intuito de reforçar alguma ideia especial, alertar para algum raciocínio e fazer sínteses) e desafiar (para levar o aluno a aprofundar e/ou ampliar o seu raciocínio, através do pedido de justificações, explicações e introdução de representações), adaptadas das categorias propostas por Ponte et al. (2013), porque a análise preliminar de dados indicou serem adequadas para caraterizar as ações da professora. Ainda no tema componentes da discussão, fez-se um reajustamento do modelo de Sherin (2002) agrupando as duas últimas componentes numa só e incluindo uma terceira designada, neste estudo, de conclusão. Quanto à análise do conhecimento didático do professor, usamos as categorias do modelo de Ponte (2012) por evidenciar uma natureza integradora das diversas vertentes do conhecimento: currículo, alunos e aprendizagem, prática letiva e Matemática.

O dispositivo de estudo é um trabalho colaborativo com três professores, que integram o projeto PPDMEA, sendo um deles (Ana) o caso de estudo aqui apresentado. A opção pela constituição de um grupo colaborativo justifica-se por ser uma estratégia poderosa de desenvolvimento profissional, particularmente, quando se pretende concretizar mudanças na prática dos professores (Hargreaves, 1998). Assim, o trabalho colaborativo permite estudar a professora, com vista a compreender a sua prática de discussão, ao longo de um ano, onde as Zetetiké, Campinas, SP, v.26, n.3, set./dez.2018, p.486-505 
DOI: https://doi.org/10.20396/zet.v26i3.8651653

discussões são perspetivadas como uma estratégia capaz de promover a aprendizagem dos alunos. Baseada nestes pressupostos, a investigadora dinamizou o PPDMEA organizado em dez sessões de trabalho presencial (SC) (com a duração de três horas cada), com o intuito de proporcionar dinâmicas de trabalho colaborativo e desenvolver a prática de discussão matemática. O PPDMEA surgiu enquadrado num modelo de formação contínua a pedido dos próprios professores. O trabalho realizado nas diversas sessões incidiu, de uma forma geral, sobre a reflexão de artigos e episódios de sala de aula relacionados com as discussões matemáticas e com os temas da Álgebra, a partir das próprias experiências dos professores, e a preparação de discussões coletivas tendo por base tarefas escolhidas pelos professores, sustentadas no modelo das cinco práticas de Stein et al. (2008).

\section{$O$ caso de Ana}

Ana é uma professora que tem, no momento do estudo, 22 anos de serviço docente. Gosta de novos desafios, apostando na participação em projetos como forma de se desenvolver profissionalmente, através da realização de aprendizagens e da reflexão sobre a sua prática. Considera que as suas aprendizagens têm repercussões na aprendizagem dos seus alunos, pois ao refletir sobre a sua prática introduz mudanças no ensino que os afetam. No caso da participação no PPDMEA, sublinha que o seu interesse se prende com a procura de novas propostas didáticas que lhe permitam evitar o formalismo da linguagem que está, muitas vezes, associada aos conteúdos algébricos: "Eu acho que é outra vez para ver (...) se pode ensinar isto de outra maneira, pronto, ou até o que me está a preocupar é um bocado o formalismo" (EI set 2013). Ana é uma professora experiente, aberta a novas propostas, principalmente, aquelas que lhe permitem lançar um novo olhar sobre a sua prática, como foi esta do projeto das discussões matemáticas (PPDMEA).

\section{Preparação da discussão coletiva}

\section{Tarefas e propósito da discussão}

A professora atribui grande importância à escolha das tarefas matemáticas a propor aos alunos, já que são elas que desencadeiam a sua atividade matemática: "É muito importante o tipo de tarefas que (...) lhes propomos, porque acho, se for uma coisa muito aberta há alguma tendência deles se perderem e nós também (...) O objetivo depois não é alcançado com a facilidade que devia." (EI set 2013). Para Ana, as tarefas não devem ser de natureza muito aberta, na medida em que isso pode comprometer o trabalho dos alunos e, consequentemente, o propósito que define para a discussão, já que se os alunos não conseguirem avançar na resolução da tarefa podem não existir estratégias de resolução a discutir. Baseada nestes pressupostos, no grupo colaborativo (GC), Ana escolhe a tarefa $A$ cantina da escola, de entre um conjunto de tarefas apresentadas pela investigadora para abordar o tópico resolução de equações do $1 .^{\circ}$ grau com uma incógnita. A sua opção por introduzir adaptações à tarefa resulta de a proposta inicial sugerir somente o trabalho com equações envolvendo denominadores e Ana pretender diversificar mais as condições iniciais, de modo a levar os alunos a interpretar informação que implique, na sua tradução para 
DOI: https://doi.org/10.20396/zet.v26i3.8651653

linguagem matemática, o uso de denominadores e das operações multiplicação e adição, como discutido no GC: "A tarefa ficava a ganhar se as condições fossem alteradas, de forma a envolver mais operações numéricas, o uso de parêntesis e denominadores. Também favorecia a atribuição de diferentes designações à incógnita” (NC_27 mar 2014). Assim, após as adaptações, a tarefa apresentada por Ana aos alunos é a da Figura 2:

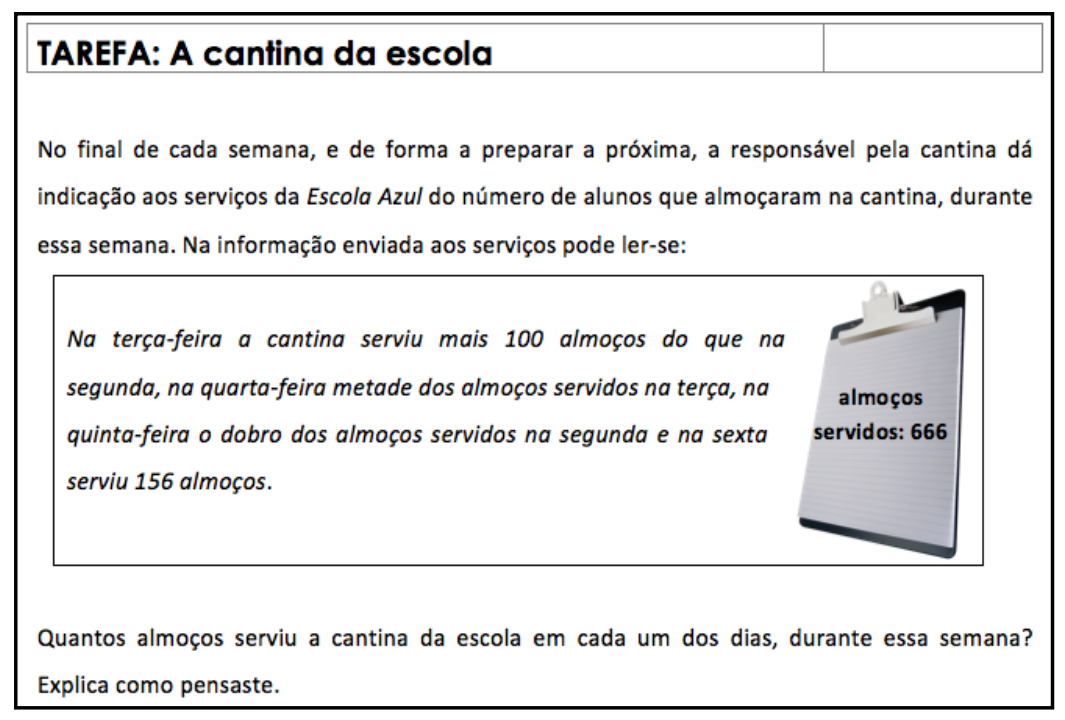

Figura 2 - Tarefa A cantina da escola

Fonte: Autores do estudo

Esta tarefa é um problema (tarefa de natureza fechada e desafio elevado) que requer que os alunos interpretem informação apresentada em linguagem natural e a traduzam para linguagem matemática. Quando seleciona a tarefa, Ana tem o cuidado que esta esteja relacionada com os conteúdos programáticos que está a abordar no momento e com os temas que estão a ser trabalhados no PPDMEA.

A tarefa A cantina da escola surge em contexto do quotidiano dos alunos, sendo estes desafiados a encontrarem estratégias que lhes permitam determinar o número de almoços servidos. O trabalho dos alunos pressupõe que sejam capazes de definir o número de almoços servidos em cada dia da semana, em função do número de almoços servidos num certo dia, que corresponde a uma incógnita.

Esta tarefa é selecionada por Ana por ser semelhante às dos manuais escolares dos alunos e se aproximar do seu tipo de trabalho habitual. Este é um aspeto que valoriza quando pensa numa tarefa para propor aos alunos e, por essa razão, não considerou outras propostas, mais abertas, da investigadora: "Os meninos não estão habituados a este tipo de resoluções" (3. ${ }^{a}$ SC_2 dez 2013). Com essa escolha, acredita que as tarefas dos manuais permitem o envolvimento em discussões coletivas, não havendo necessidade de os professores conceberem novas tarefas. A preparação de novos recursos é um dos constrangimentos apontados muitas vezes pelos professores para não promoverem discussões coletivas em sala de aula. Com esta tarefa, Ana mostra que a prática diária do professor é compatível com a dinamização de discussões. 
DOI: https://doi.org/10.20396/zet.v26i3.8651653

O trabalho dos alunos com esta tarefa apela ao uso de representações matemáticas e não matemáticas, ao traduzirem informação em linguagem natural para linguagem matemática, através de uma equação.

Escolhida a tarefa, a planificação de Ana contempla a definição do propósito da discussão, onde identifica o conceito matemático que pretende abordar: "O objetivo é resolverem problemas com equações. Eles podem fazer tentativas mas pretendo que eles consigam traduzir o problema por uma equação" (NC_27 mar 2014). Vê a escrita da equação como a generalização das relações estabelecidas entre o número de almoços da semana, após a interpretação da informação apresentada em linguagem natural. Contudo, admite abordagens distintas da escrita da equação. Ana também identifica os objetivos específicos a alcançar pelos alunos com esta tarefa, a partir da atribuição da incógnita ao número de almoços servidos em diversos dias da semana: "Esta equação surge com parêntesis e denominadores" (NC_27 mar 2014).

Em sala de aula, Ana prossegue a preparação da discussão, verificando que os alunos são capazes de traduzir a informação apresentada por linguagem matemática, sendo surpreendida com a escrita de diferentes equações: "Eu nesse dia estava muito orgulhosa dos meus meninos (...) esta equação aparece com parêntesis (...) com denominadores" ( $8 .{ }^{\text {a }} \mathrm{SC} 8$ mai 2014). Na sua perspetiva, o aparecimento desta diversidade de equações justifica-se, como antecipado, pela atribuição da incógnita ao número de almoços servidos em diferentes dias da semana: "A turma estava dividida em três grupos [tipos de resoluções distintos] (...) há um grupo que faz a outra, há três grupos que faz esta, que é atribuir o $x$ [ao número de

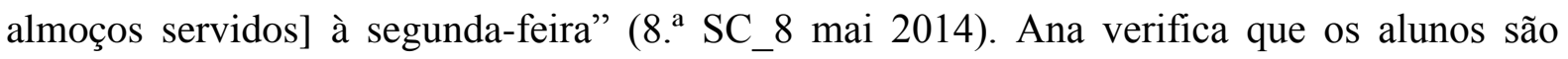
capazes de generalizar as relações implícitas na tarefa.

A professora mobiliza o seu conhecimento dos alunos e da aprendizagem na escolha das tarefas a apresentar aos alunos, na medida em que procura que as tarefas estejam de acordo com o seu trabalho habitual e não sejam demasiado abertas. Apoia-se também no seu conhecimento do currículo e da Matemática na identificação, antes e durante a aula, dos conceitos matemáticos e objetivos específicos que pretende abordar e generalizar. $\mathrm{O}$ conhecimento da Matemática, em articulação com o da prática letiva é, também, fundamental na escolha da tarefa, em particular nas representações matemáticas que poderão estar presentes no trabalho dos alunos.

\section{Estratégias de resolução}

O trabalho de antecipação de possíveis estratégias de resolução dos alunos é desenvolvido no GC, onde Ana e os seus colegas preveem o aparecimento da estratégia de tentativa e erro:

Os alunos podem resolver este problema por tentativa, atribuindo um determinado número de almoços à segunda ou à terça e definindo o número de almoços dos outros dias à custa deste. Podem trabalhar com os cinco dias da semana e o total de almoços ou apenas com quatro dias da semana e com 510 almoços (...) Podem iniciar as suas tentativas por um número redondo. (NC_27 mar 2014) 
DOI: https://doi.org/10.20396/zet.v26i3.8651653

Ana prevê que os alunos iniciem as suas tentativas com números como o 50 ou o 100 escolhidos arbitrariamente e que possam trabalhar com toda a informação apresentada no enunciado, ou que façam uma boa análise das condições dadas e, a partir daí, trabalhem apenas com quatro dias da semana. Antecipa, também, a estratégia algébrica, através da escrita de uma equação:

Os alunos podem também traduzir este problema por uma equação. Os alunos que consideram o número de almoços servidos na segunda a incógnita $(x)$, obtêm para terça a expressão $x+100$, para quarta $\frac{1}{2}(x+100)$ e para quinta $2 x$. Neste caso, pode ocorrer a situação de os alunos não colocarem parêntesis na informação de quarta. Face a este erro, os alunos são desafiados a traduzir por linguagem corrente o que têm representado e comparar com a informação dada. Os alunos que atribuem à incógnita o número de almoços de terça-feira $(x)$, obtêm para segunda a expressão $x 100$, para quarta $\frac{1}{2} x$ e para quinta $2(x$ 100). (NC_27 mar 2014)

Para além de prever possíveis estratégias, Ana (com os seus colegas de GC) pensa, também, em possíveis dificuldades dos alunos, definindo, nesse caso, o tipo de ajuda a prestar. Ana considera fundamental este momento de antecipação de estratégias a apresentar pelos alunos, porque tem reflexos na sua aprendizagem:

Eu não fazia de forma tão cuidada a preparação das aulas no sentido de antecipar as resoluções (...) agora é de uma forma muito mais organizada (...) voltou acontecer em testes, aquilo funcionou (...) organizar o que lhes é dado no texto numa tabela, isso trouxe-lhes alguma segurança e vi que pode haver coisas que vamos continuar a dar porque funcionaram e vale a pena insistir. (EF jun 2014)

Ana destaca a mobilização dessas estratégias em situações futuras, como é o caso das provas escritas de avaliação. Em particular, salienta a estratégia de realização de uma tabela como um elemento marcante do trabalho dos alunos, principalmente na organização da informação do enunciado. Justifica esta mudança na sua prática de antecipação de estratégias com a leitura e reflexão do artigo Ensino exploratório da Matemática: práticas e desafios nas sessões de trabalho colaborativo: "Foi depois daquele artigo, de vermos aquelas etapas (...) eu dei por mim a (...) tentar ver, (...) antecipar algumas, claro que às vezes é giro termos surpresas, não é?" (EF jun 2014). Ana salienta a imprevisibilidade que pode ocorrer em sala de aula, já que podem surgir estratégias de resolução não antecipadas. Contudo, o facto de pensar previamente sobre isso dá-lhe mais segurança para lidar, em sala de aula, com estratégias diferentes das antecipadas.

$\mathrm{Na}$ aula, Ana identifica nos trabalhos dos alunos a estratégia por tentativa e erro: "Há um grupo que faz mais por tentativas, mas o engraçado nos outros é começar por um número redondo. Portanto, começam por 100 e depois vão subindo ou descendo. Não tem nada a ver com esta que dividem logo" (8. ${ }^{\text {a }}$ SC_8 mai 2014).

Ana releva o raciocínio metódico desenvolvido por um grupo de alunos que escolhe criteriosamente um número resultante da análise das condições do enunciado, especificamente, começam por retirar ao total de almoços o número de almoços conhecido e, 
DOI: https://doi.org/10.20396/zet.v26i3.8651653

de seguida, dividem o resultado pelos quatro dias da semana. Esse raciocínio é surpreendente para Ana, já que só tinha antecipado a experimentação de números arbitrários como 50 ou 100. A aposta na experimentação de números arbitrários pode estar relacionada com a prática anterior da professora. Pode também resultar da estratégia por tentativa e erro ser menos exigente do ponto de vista matemático e, nessa medida, ser esperado que os alunos avancem logo para a realização de tentativas e não se preocupem tanto em procurar interpretar a informação dada, de modo a poder manipulá-la de outra forma.

A estratégia algébrica é também identificada pela professora nos trabalhos dos alunos, onde escrevem duas equações distintas em resultado da atribuição da incógnita a números de almoços em dias da semana diferentes:

Há um grupo que faz a outra, há três grupos que faz esta, que é atribuir o $x$ à segunda-feira (...) então agora a outra é. (...) A terça-feira, exato. Portanto segundafeira é $x 100$, terça é $x$, quarta é $\frac{x}{2}$ e depois. (...) Esta resolução aparece uma vez ainda, pronto, acho que é giro. Com parêntesis, com denominadores. (8. ${ }^{a}$ SC_8 mai 2014)

Ana constata que este tipo de estratégia é privilegiado pelos alunos, sendo mais frequente a atribuição da incógnita ao número de almoços de segunda-feira. Contudo, surge também uma equação onde a incógnita representa o número de almoços de terça-feira. Em ambas as situações, os alunos resolvem equações com parêntesis e denominadores.

$\mathrm{Na}$ antecipação e na identificação em sala de aula das estratégias dos alunos, Ana mobiliza o seu conhecimento da Matemática. Esse conhecimento é útil para reconhecer diferenças nas estratégias apresentadas pelos alunos em função do antecipado. A professora destaca as aprendizagens por si realizadas como resultado da sua participação no PPDMEA, em particular, no que se refere à antecipação de possíveis estratégias a desenvolver pelos alunos no seu trabalho com as tarefas propostas.

\section{Seleção de estratégias e trajetórias de sequenciação}

Baseada no trabalho realizado no GC, Ana prevê selecionar, para apresentação na aula, as estratégias de resolução que envolvam representações diversificadas (algébrica e não algébrica) e organizar as intervenções dos alunos de modo a evidenciar a transição da linguagem matemática informal para a formal: "O processo com recurso à tabela [com tentativas] seria partilhado em primeiro lugar seguido da estratégia que usa uma equação" (NC_27 mar 2014). Em sala de aula, de acordo com o planificado, Ana escolhe para iniciar a apresentação as estratégias que envolvem representações não algébricas: "Apenas um dos grupos resolveu o problema por tentativa e erro tendo, no entanto, denotado um raciocínio consistente" (9. ${ }^{a}$ SC_ 15 mai 2014). Esse raciocínio diz respeito à interpretação que os alunos fazem das condições do enunciado, ou seja, retiram ao total de almoços o número de almoços conhecidos e dividem o resultado por quatro. Neste caso, os alunos não experimentam valores arbitrários, mas escolhem um número que reflete um conjunto de operações de acordo com os dados. Esta estratégia surge apenas na resolução de um grupo, embora Ana pensasse 
DOI: https://doi.org/10.20396/zet.v26i3.8651653

que pudesse vir a ser adotado por mais alunos: "Eu estava convencida que esta resolução [por tentativas] até ia aparecer em mais grupos" ( $8 .{ }^{\text {a }} \mathrm{SC} \_8$ mai 2014). Embora esta estratégia de resolução não tenha sido antecipada pela professora, consegue-a introduzir na sua preparação da discussão na aula, pois já tinha pensado previamente noutras semelhantes.

Seguidamente, Ana escolhe as estratégias de resolução que envolvem representações algébricas:

A maioria dos grupos utilizou resoluções algébricas, embora diferentes de grupo para grupo. (...) Esta resolução foi adotada por dois grupos, é a resolução que nos parece mais expectável [atribuição da incógnita ao valor de segunda-feira], de acordo com a leitura do enunciado. (...) Nesta resolução, a variável representa o número de almoços de terça-feira, tendo contribuído para uma maior complexidade da equação. (9. ${ }^{a} \mathrm{SC}_{-}$ 15 mai 2014)

Ana é surpreendida por esta estratégia na maioria dos grupos, justificando a atribuição da incógnita com a formulação do problema. Contudo, o facto de os alunos também atribuírem a incógnita a outro ente, favorece a resolução de equações envolvendo procedimentos diferentes, como o uso de denominadores e parêntesis. Para a professora, "Os alunos mostram ser capazes de estabelecer estratégias informais e, progressivamente, de usar também estratégias mais formais para resolver problemas, o que pressupõe o desenvolvimento da sua compreensão da linguagem algébrica” (RI_jul 2014).

Ana recorre ao seu conhecimento da Matemática e da aprendizagem e dos alunos na seleção das estratégias de resolução e na sequenciação que estabelece para os convidar a partilhar com a turma. Estes conhecimentos são fundamentais na organização das intervenções dos alunos, pois decide iniciar pela estratégia menos frequente e menos poderosa do ponto de vista algébrico (tentativa e erro), avançando para estratégias que usam representações algébricas. Neste caso, inicia pelas estratégias mais frequentes (atribuição da incógnita ao valor de segunda-feira), deixando para último a menos frequente (atribuição da incógnita ao valor de terça-feira). Este encadeamento favorece o avanço na formalização da linguagem matemática.

\section{Dinamização da discussão coletiva}

$\mathrm{Na}$ aula, após o trabalho dos alunos em grupo, Ana inicia a apresentação das estratégias de resolução com o convite a um aluno - ação de elicitar. Decide iniciar pela estratégia menos utilizada pela turma, que faz uso da estratégia por tentativa e erro através de uma tabela (Figura 3), como evidencia o diálogo:

Rui: Nós fizemos por tentativas (...) Na semana toda foram servidos 666 almoços e nós tirámos logo 156 que foi o da sexta, que deu 510. Depois dividimos 510 por 4. Professora (P): Porquê? Explica lá. (...)

Rui: Porque estamos a retirar este para dar, porque tudo somado tem que dar 510.

P: Conclusão, que corresponde aos 4 primeiros dias que estão ali em falta, não é? (...)

Rui: Começámos com 128 na segunda.

P: Pronto, e agora se calhar tens que explicar aos colegas. O 128 já todos perceberam e os outros números de onde vêm?

Rui: Vêm do que está aqui. (...)

Zetetiké, Campinas, SP, v.26, n.3, set./dez.2018, p.486-505

ISSN 2176-1744 
DOI: https://doi.org/10.20396/zet.v26i3.8651653

P: Ao que está no texto [enunciado]. Então, as contas estão feitas de acordo a obedecerem ao texto. (...) Depois viram então que não funcionava e... (Aula_Equações_abr 2014)

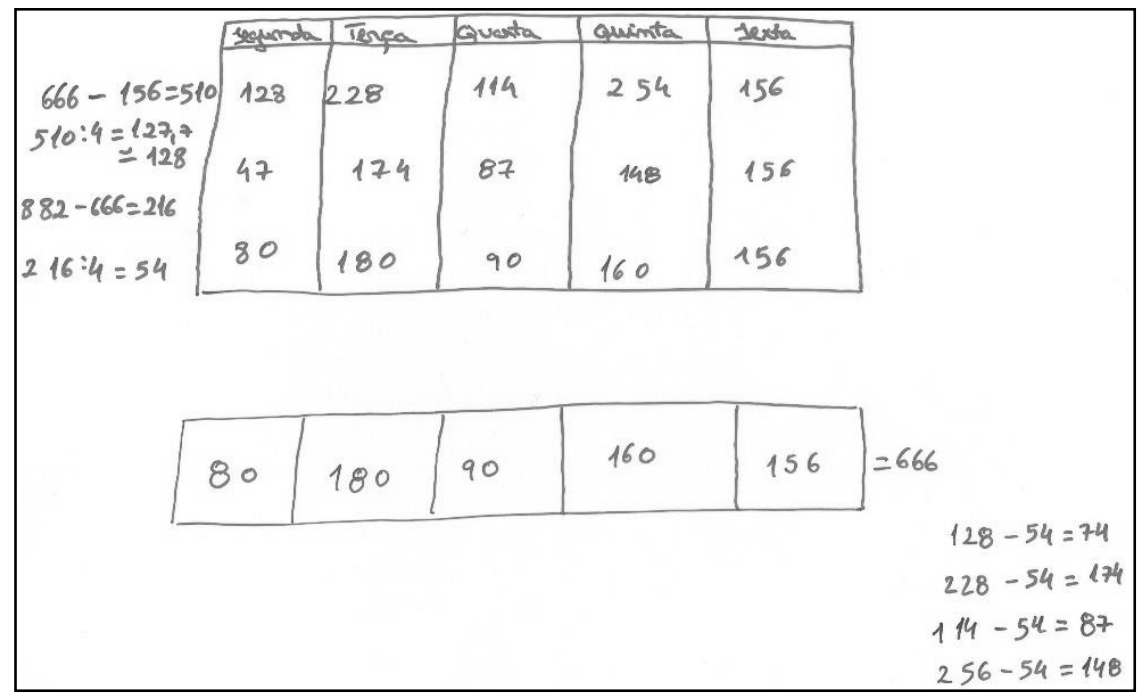

Figura 3 - Estratégia envolvendo tentativa e erro

Fonte: Autores do estudo

A estratégia que escolhe para iniciar a apresentação não se baseia na experimentação arbitrária de números, mas na escolha criteriosa de um número, resultante da interpretação e manipulação das condições do problema. Assim que o aluno começa a explicação da estratégia, Ana recorre a ações de desafiar para o levar a redizer a explicação, por envolver um raciocínio que pode não ser imediatamente compreendido pelos colegas, já que normalmente quando recorrem à estratégia por tentativa o fazem pela experimentação arbitrária de números, podendo experimentar números aleatórios ou começar por números redondos, como previsto. Com esta ação, Ana pretende negociar o procedimento adotado pelo grupo de alunos que está apresentar. Perante a explicação do aluno, recorre a ações de apoiar para completar o seu contributo e para concordar com o exposto. Pretende incentivar o aluno a avançar com a sua explicação. Volta a recorrer a ações de desafiar para levar o aluno a explicar o raciocínio seguido para obtenção dos outros números que constam da tabela. Perante a correção da explicação, Ana socorre-se de ações de apoiar para manifestar concordância e para redizer o argumento do aluno, usando linguagem mais precisa. Utiliza ainda estas ações para incentivar o aluno a continuar, iniciando uma afirmação que deve ser concluída pelo aluno. Os alunos correspondem ao pedido e continuam a explicar o seu raciocínio:

Tomás: Eu fui ao total dos almoços, subtraí os almoços totais que era para ver quantos almoços sobravam.

P: Quanto é que tem a mais neste momento.

Tomás: Depois dividi o resultado por 4 que era para saber o que tinha que subtrair. (...)

Guilherme: Ó stora, 510 a dividir por 4 dá 127 e meio.

Tomás: Sim, nós arredondámos para 128. (...) Porque para, por exemplo para ser metade tinha que ser um número par. (...) 
DOI: https://doi.org/10.20396/zet.v26i3.8651653

Rui: Experimentámos outra, o 74.

P: E donde vem o 74 ?

Tomás: Da subtração. Fizemos. Fomos ao 128. Primeiro dividimos 216 por 4 para saber quanto é que ia ficar pelos 4 .

P: Para cada um deles. Quanto é que tinham que tirar a cada um.

Tomás: Sim. Depois fomos ao 128 e subtraímos o resultado da divisão.

P: E essa conta não têm aí. (...) Exatamente, porque a sexta é fixa e já não temos que pensar na sexta, estão a ver? Portanto, na prática eles têm 216 almoços a mais do que deviam. Então supostamente, este 74 é o 128 menos o 54. (...) Então agora tiraram isso a todos. (Aula_Equações_abr 2014)

À medida que Tomás vai explicando o raciocínio, Ana recorre às ações de apoiar para redizer o seu argumento, de modo a que fique claro para todos. Este episódio mostra o envolvimento da turma na explicação do grupo inicial, já que Guilherme coloca uma questão pertinente que permite introduzir um aspeto importante que tinha sido esquecido pelo aluno que está a expor a sua estratégia. Neste segmento, Ana volta a recorrer a ações de desafiar através do pedido de justificações para o argumento introduzido. Usa, também, as ações de apoiar para redizer o argumento do aluno e para fazer uma breve síntese do que foi explicado, de modo a envolver os alunos na construção dos raciocínios.

Ana promove a comparação de estratégias de resolução, informando a turma do número de estratégias que serão partilhadas - ações de informar, como se evidencia a seguir:

P: Pronto, então se calhar agora íamos ver (...) mais duas. (...) O que é que escreveste aí? Porquê? Vais explicar a primeira parte.

Renato: Na terça diz que serviu mais 100 almoços do que na segunda. Então na segunda como não sabíamos, pus $X$. Depois na terça-feira fiz $X$ mais 100 que é os almoços servidos. Depois, na quarta-feira diz que é metade dos almoços servidos, temos que meter entre parêntesis para fazer primeiro o que está lá dentro. Na quintafeira diz que é o dobro dos almoços da segunda e na sexta os 156 almoços. (...)

P: Esta é igual à vossa, não é? E acho que é igual à deles ali também. (...) Estamos a somar os dias da semana todos e sabemos que tem que dar os 666 almoços. (...) vocês repararam que o Renato já fez ali umas alterações da expressão que ele tinha ali ao lado para a expressão que passou para a equação? (...) mudou o que escreveu na quarta-feira e já pôs ali com um traço de fração. E é aquilo que vocês estão mais habituados a utilizar, porque se pusessem a dividir por 2 , podem, teriam mais algumas dificuldades ali na resolução e também já transformou o $x$ vezes $2 \mathrm{em} 2 x$, está bem? (...) Ou seja, $x$ é igual. (...) Pronto, então agora chegámos ao fim da equação, mas quando chegamos ao fim da equação ainda não estamos no fim do problema. (...) Vá, o que é que escreves? (Aula_Equações_abr 2014)

Ana seleciona o aluno que continua a apresentação de estratégias de resolução, avançando para as mais frequentes e que recorrem a linguagem algébrica (Figura 4). 


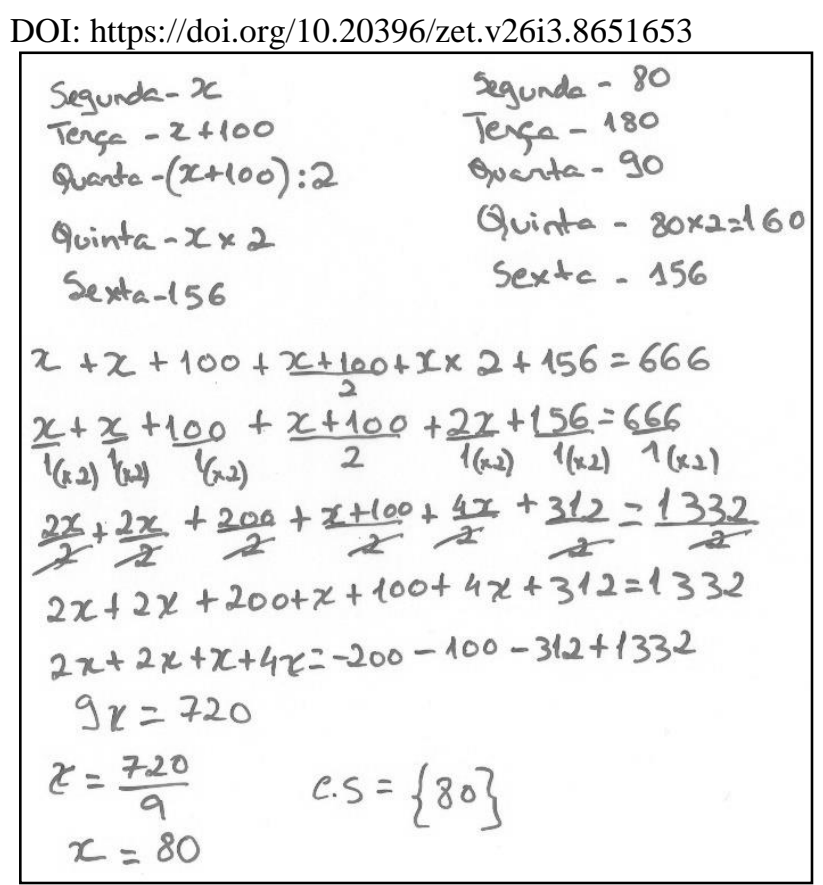

Figura 4 - Estratégia algébrica

Fonte: Autores do estudo

A professora apoia-se em ações de desafiar para levar o aluno a explicar o raciocínio seguido, em particular, o monómio que representa cada dia da semana. Perante a clareza da explicação apresentada, usa as ações de apoiar para o animar a avançar com a sua explicação. De seguida, menciona as estratégias que surgiram na turma iguais à apresentada ações de informar. Pretende, com essa ação, incentivar os alunos a acrescentar contributos, através da comparação da sua estratégia com a exibida. Recorre, ainda, a estas ações para alertar a turma das alterações que o aluno faz nos monómios que figuram na equação inicial e os que usa na resolução da equação, em particular, a passagem da divisão à representação sob a forma de fração e a supressão do sinal de multiplicação - filtragem. Ana sente necessidade de negociar estes conceitos, já que são monómios mais fáceis de mobilizar na resolução da equação, pretendendo que sejam compreendidos por todos. Estas ações são também úteis para reforçar a necessidade da indicação da resposta ao problema, destacando que a resolução de um problema não termina com a resolução da equação.

Ana continua a promover a comparação de estratégias, através da introdução de mais uma estratégia de resolução que caracteriza como sendo semelhante à apresentada mas que surge isolada na turma e consiste na atribuição da incógnita à terça-feira. $\mathrm{O}$ comentário da professora provoca reações inesperadas nos alunos:

Guilherme: Idêntica, mas diferente.

P: Hã? Idêntica, mas diferente. Reparem, o que é que está diferente? Tem um denominador e tem parêntesis, que a outra não tinha. (...) Então o que é que tu achas, de acordo com o resultado que ali está, o que é que vai ter que dar o nosso $X$ ?

Guilherme: 180 .

P: Foi isso que aconteceu. (...) Está agora a juntar a segunda, com a terça, com a quarta, com a quinta e com a sexta. (...) Vai dar $X$ igual a 180 .

Íris: Porque o nosso $x$ é terça-feira. 
DOI: https://doi.org/10.20396/zet.v26i3.8651653

P: Ora repara, se aqui é 180, este grupo agora para chegar a segunda-feira o que teve que fazer? (...) Tirar 100. Conclusão, dá os 80 dali. (Aula_Equações_abr 2014)

A avaliação que o aluno faz da sua afirmação permite a Ana dar continuidade à discussão, levando os alunos a antecipar o conjunto solução da equação anterior, antes da sua resolução - ação de desafiar. Pretende levar os alunos a relacionar a resposta dada ao problema com a solução da equação, compreendendo que a resposta ao problema se mantém mesmo quando é traduzido por uma equação diferente. Perante a correção da resposta do aluno, recorre a ações de informar para salientar que o aluno tem razão. Contudo, ainda, incita a aluna a explicar como deu resposta ao problema - ação de desafiar. Ana pretende que os alunos concluam que o mesmo problema pode ser traduzido por equações distintas, com conjuntos-solução também diferentes mas que originam a mesma resposta ao problema e que a resolução de um problema só termina com a apresentação da resposta. Com esse propósito, conclui a discussão salientando que a mesma informação apresentada em linguagem natural pode ser traduzida em linguagem matemática por equações distintas: "Olhem, todos resolveram o mesmo problema mas as equações eram ligeiramente diferentes" (Aula_Equações_abr 2014) - conclusão.

Durante a dinamização da discussão, Ana organiza o discurso de modo a evidenciar a transição do uso da linguagem matemática informal para a formal, através da generalização das relações encontradas e visível na escrita de uma equação. Inicia a apresentação com o convite à exibição das estratégias de resolução - solicitação e discussão de muitas ideias avançando para a análise de mais duas estratégias de resolução distintas das apresentadas e que recorrem à escrita de uma equação, como antecipado na sua planificação - filtragem - e mais potentes do ponto de vista da utilização de linguagem algébrica. A análise de uma das estratégias desencadeia uma nova solicitação de ideias em torno da associação do conjunto solução da equação com a resposta ao problema - solicitação e discussão de mais ideias. No início da discussão, pretende ter muitos raciocínios em análise - conteúdo matemático não filtrado - para, seguidamente, focar a análise dos alunos na comparação dessa estratégia com outras duas que recorrem a linguagem matemática diferente - conteúdo matemático filtrado.

$\mathrm{Na}$ dinamização da discussão, Ana apoia-se no seu conhecimento da prática letiva, em articulação com o da Matemática e o da aprendizagem e dos alunos na forma como promove a discussão, especialmente nas estratégias que escolhe para iniciar a partilha e como continua a discussão através da comparação, da avaliação e da filtragem. Usa também esses conhecimentos para deixar os alunos responderem às questões dos colegas e também na forma como fecha a discussão, salientando a conexão entre linguagens matemáticas diferentes.

\section{Conclusão}

Este estudo revela quão exigente é para o professor preparar e dinamizar discussões coletivas que levem os alunos a aprender Álgebra de forma produtiva. A prática de discussão da professora em sala de aula foi potenciada pela preparação da discussão, em íntima relação 
DOI: https://doi.org/10.20396/zet.v26i3.8651653

com as diversas vertentes do seu conhecimento didático. A Figura 5 ilustra as relações entre o conhecimento didático e a prática de discussão matemática do professor, nas suas diversas fases, momentos e dimensões.

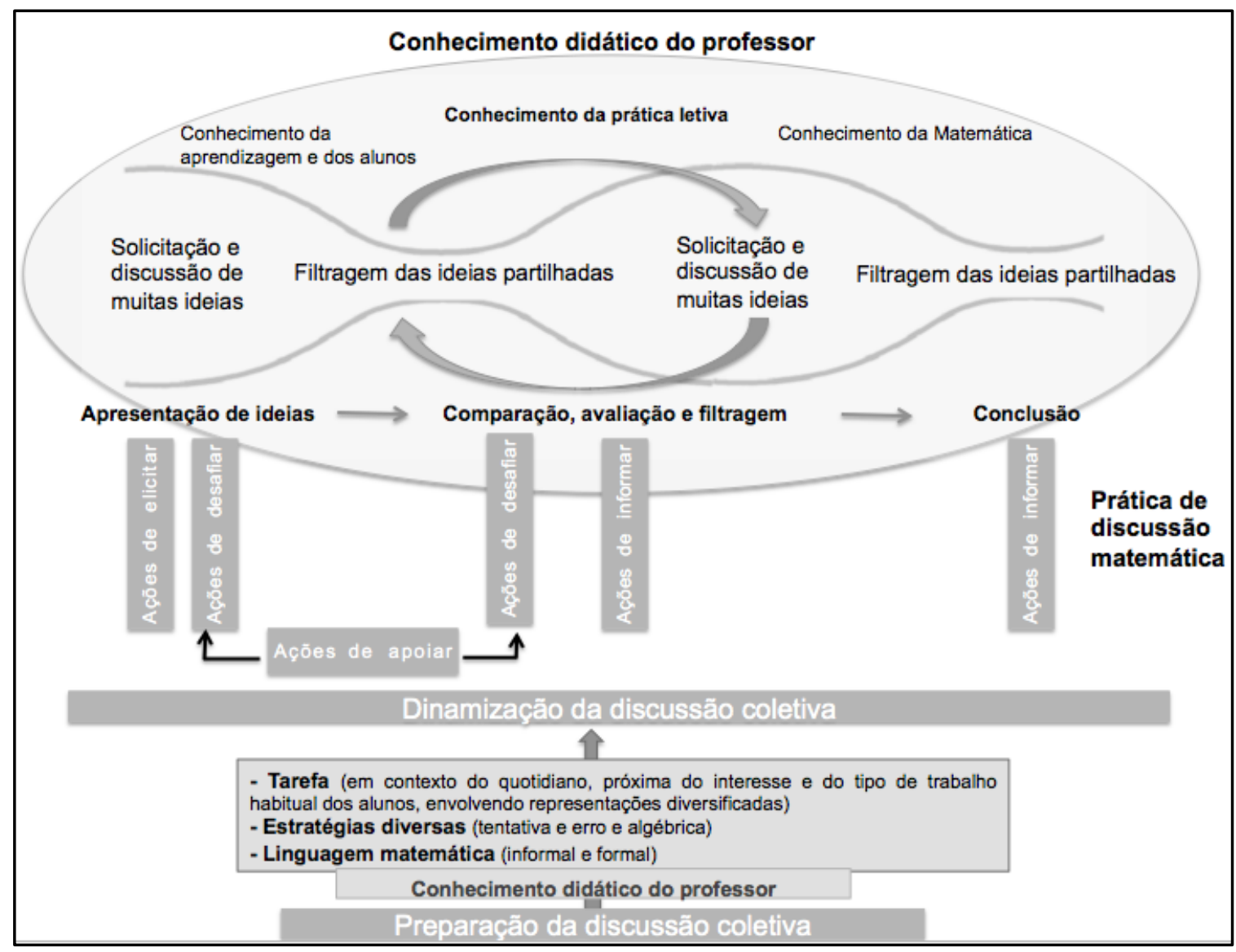

Figura 5 - Preparação e dinamização de discussões matemáticas

Fonte: Autores do estudo

Na preparação da discussão coletiva, a professora, apoiada no seu conhecimento didático, começa por escolher tarefas que não sejam abertas nem distantes do tipo de trabalho a que os alunos estão habituados. De acordo com estes pressupostos, seleciona o problema, depois de o adaptar, para levar os alunos a interpretar informação e traduzi-la para linguagem matemática, com o objetivo de aprofundar a resolução de equações do $1 .^{\circ}$ grau com uma incógnita. Esta tarefa, com um contexto do quotidiano, apela ao uso de representações matemáticas e não matemáticas. Na preparação, a professora antecipa estratégias que recorrem a tentativa e erro e a procedimentos algébricos, através da escrita de equações, em função da atribuição da incógnita a entes diferentes. Face a estas estratégias, estabelece que os alunos serão introduzidos na discussão pela estratégia que recorre à tentativa e erro, seguida da estratégia algébrica, de modo a transitar da linguagem matemática informal para a formal. Em sala de aula, a professora observa que os alunos traduzem o problema por equações diferentes, em consequência de terem atribuído a incógnita a entes distintos. Verifica que as estratégias antecipadas emergem nas resoluções dos alunos, sendo 
DOI: https://doi.org/10.20396/zet.v26i3.8651653

surpreendida, na estratégia por tentativa e erro, com a escolha criteriosa do número para iniciar as tentativas.

Ana, apoiada no seu conhecimento didático, dinamiza a discussão coletiva em três momentos principais: (i) apresentação; (ii) comparação, avaliação e filtragem; e (iii) conclusão. A apresentação das estratégias de resolução tem início com o convite a um aluno para partilhar a estratégia por tentativa e erro. Promove depois a comparação através da introdução de mais duas estratégias - estratégia algébrica - iniciando com a mais frequente. Fomenta a avaliação através da manifestação de não concordância dos alunos face a afirmações suas. Desenvolve a filtragem levando os alunos a refletir sobre alterações de representações. Usa a conclusão da discussão visando alertar a turma para a tradução da mesma informação por diferentes equações, com a mesma resposta ao problema. A opção por selecionar sempre os alunos a apresentar as suas estratégias e não solicitar voluntários justifica-se na justa medida em que assim alcança mais eficazmente o propósito definido para aquela discussão. Além disso, ao agir de outra forma poderia comprometer o envolvimento dos alunos na generalização de relações matemáticas, uma vez que o primeiro aluno a apresentar poderia logo introduzir a estratégia algébrica não fazendo depois "sentido" a apresentação das estratégias não algébricas.

O discurso promovido pela professora denota o seu empenho em envolver os alunos na transição do uso de linguagem matemática informal para linguagem formal, através da escrita de equações. O discurso tem início com o convite à apresentação de estratégias solicitação e discussão de muitas ideias - evoluindo, intencionalmente, para a comparação de mais estratégias de resolução que mobilizam linguagem matemática formal, como antecipado - filtragem - que leva à solicitação e discussão de mais ideias. Durante o discurso, a professora evidencia intenções distintas com o que está a ser partilhado, já que no início pretende ter uma estratégia em discussão - conteúdo matemático não filtrado - para, seguidamente, focar a atenção dos alunos na comparação dessa estratégia com as outras que surgiram na turma - conteúdo matemático filtrado.

Durante a dinamização da discussão coletiva, a professora realiza diversas ações de ensino para envolver os alunos. Recorre às ações de elicitar para convidar um aluno a apresentar a sua estratégia de resolução. Usa ações de apoiar para completar contributos dos alunos; mostrar concordância; redizer informação apresentada, usando linguagem adequada; levar os alunos a completar ideias introduzidas por si; fazer sínteses; incentivar os alunos a avançar com explicações; e levá-los a antecipar relações. As ações de informar permitem-lhe indicar o número de estratégias diferentes, justificar a introdução de mais grupos na discussão, aludir a alterações de representações e informar sobre a correção dos raciocínios oferecidos. Apoia-se em ações de desafiar para solicitar explicações e justificações (como também acontece no estudo de Ponte et al. (2013)), relacionar representações e levar os alunos a redizerem explicações.

A professora recorre a ações de desafiar para levar os alunos a explicar e justificar raciocínios, mas as ações de apoiar, sob a forma de manifestação de concordância, de redizer argumentos e de promover sínteses, foram também fundamentais para alcançar esse 
DOI: https://doi.org/10.20396/zet.v26i3.8651653

propósito. As ações de desafiar passam, ainda, por levar os alunos a relacionar representações, onde esse objetivo é atingido com o suporte das ações de apoiar, através do completamento de esclarecimentos dos alunos e do oferecimento de interpretações. As ações de desafiar que permitiram aos alunos antecipar respostas e relacionar o conjunto solução de uma equação com a resposta ao problema foram apoiadas pelas ações de informar, através da validação de respostas. As ações de desafiar da professora, que visam desenvolver nos alunos uma compreensão aprofundada da resolução de problemas envolvendo equações mostram-se decisivas, mas precisam de ser apoiadas por ações de apoiar e de informar, e não usadas isoladamente, como também sugere o estudo de Cengiz et al. (2011). Neste estudo, as ações de elicitar surgem, essencialmente, associadas aos momentos de apresentação e comparação de estratégias, surgindo articuladas com as restantes, de modo diferente ao estudo de Ponte e Quaresma (2016), onde as ações de informar surgem sobretudo relacionadas com os momentos de síntese. As ações de elicitar são as menos expressivas nesta discussão, devido ao seu próprio objetivo - introduzir o aluno na discussão - sendo as mais expressivas as de apoiar, já que contribuem para fazer os alunos progredir na discussão, mostrando-se determinantes no envolvimento dos alunos na discussão, estabelecendo conclusões importantes relacionadas com a resolução de problemas envolvendo equações.

Em suma, esta investigação revela a importância do estudo da prática de discussão coletiva em Matemática, dada a complexidade e exigência dessa atividade letiva enquanto promotora da aprendizagem dos alunos, com vista a favorecer uma melhor compreensão matemática. Mais do que estabelecer o tipo de ações que o professor deve desempenhar em cada momento da discussão, trata-se de compreender quais as opções que tem ao seu alcance e quais as suas consequências para o processo de aprendizagem dos alunos.

\section{Referências}

Bardin, L. (1994). Análise de conteúdo. Lisboa: Edições 70.

Cengiz, N., Kline, K., \& Grant, T. J. (2011). Extending students' mathematical thinking during whole-group discussions. Journal of Mathematics Teacher Education, 14(5), 355374.

Guerreiro, A., Ferreira, R., Menezes, L., \& Martinho, H. (2015). Comunicação na sala de aula: a perspectiva do ensino exploratório da matemática. Zetetiké, 23(44), 279-295.

Hargreaves, A. (1998). Os professores em tempos de mudança: O trabalho e a cultura dos professores na idade pós-moderna. Lisboa: Mc Graw-Hill.

Menezes, L., Guerreiro, A., Martinho, M. H., \& Tomás Ferreira, R. (2013). Essay on the Role of Teachers' Questioning in Inquiry-Based Mathematics Teaching. Sisyphus - Journal of Education, 1(3), 44-75.

Ponte, J. P. (2012). Estudiando el conocimiento y el desarrollo profesional del profesorado de matemáticas. In N. Planas (Ed.), Educación matematics: Teoría, critica y prática (pp. 83-98). Barcelona: Graó.

Ponte, J. P. (2006). Estudos de caso em educação matemática. Bolema, 25, 105-132. 
DOI: https://doi.org/10.20396/zet.v26i3.8651653

Ponte, J. P., Mata-Pereira, J., \& Quaresma, M. (2013). Ações do professor na condução de discussões matemáticas. Quadrante, 22(2), 55-81.

Ponte, J. P. \& Quaresma, M. (2016). Teachers' professional practice conducting mathematical discussions. Educational Studies in Mathematics, 93, 51-66.

Sherin, M. G. (2002). A balancing act: Developing a discourse community in a mathematics classroom. Journal of Mathematics Teacher Education, 5(3), 205-233.

Smith, M., \& Stein, M. K. (2011). 5 practices for orchestrating productive mathematics discussions. Reston, VA: National Council of Teachers of Mathematics.

Stein, M. K., Engle, R. A., Smith, M. S., \& Hughes, E. K. (2008). Orchestrating productive mathematical discussions: five practices for helping teachers move beyond show and tell. Mathematical Thinking and Learning, 10(4), 313-340. 